\title{
CHALLENGES IN THE DEVELOPMENT OF STANDARDS FOR SYNTHETIC TURF FOR AUSTRALIAN FOOTBALL AND CRICKET
}

Dara M Twomey, Leonie Otago, Natalie Saunders

School of Human Movement and Sport Sciences, University of Ballarat, Victoria, Australia

Corresponding Author

Dara Twomey

School of Human Movement \& Sport Sciences

University of Ballarat,

PO Box 663

Ballarat

VIC 3353

Australia

d.twomey@ballarat.edu.au 


\section{ABSTRACT}

Given the escalating drought conditions in Australia, synthetic surfaces have recently been explored as a viable surface option for community level Australian football/cricket ovals. The vast majority of Australian football ovals are transformed into cricket pitches during the football offseason and hence the characteristics of both sports had to be duly considered in the development of standards that could be tested in a laboratory setting, for a synthetic turf surface. This paper describes the data collection and test methods undertaken in the development of the standards for synthetic surface use in Australian football and cricket. The paper also discusses the issues and challenges encountered during the development of standards for multi-sport synthetic surfaces to ensure player safety while maintaining the performance characteristics of both sports. Surface property and ball interaction tests were undertaken on natural playing surfaces, both in situ and in the laboratory to determine the properties of the current playing surface for each sport. This paper highlights the importance of careful consideration of the characteristics of both games and the use of equipment from both sports in the testing methods. The standards described in this paper have now been accepted by the Australian Football League and Cricket Australia and the product approval process and use of synthetic surfaces for Australian football and cricket is imminent.

Keywords: synthetic turf, Australian football, cricket, playing standards 


\section{INTRODUCTION}

Sports such as Australian football and cricket are an integral part of life in Australia and natural grass has traditionally been used for Australian football and cricket outfields. However, given current climate changes and drought experienced in many parts of Australia, the degradation of natural grass surfaces is becoming a significant problem. This problem encapsulates such issues as stringent restrictions on watering grounds and insufficient rainfall; the limited use of natural turf grounds due to substandard conditions and the closure of grounds through safety concerns [1]. Hence, the use of synthetic turf surfaces has been suggested as a possible solution to this problem.

Synthetic turf has undergone significant developments in the past few decades. The earliest product in the 1960's, a high density carpet called Astroturf, launched the synthetic turf industry. Developments continued throughout the subsequent years, with the emergence of the latest products known as 'third generation turf' in the late 1990's [2]. Third generation turf comprises longer synthetic fibres (approximately $65 \mathrm{~mm}$ ) than the earlier generations and is currently in-filled with sand and rubber granules. This generation of turf has been used for many years in Europe and the USA, but has made little impact in the Australian market to date. However, facing significant climatic issues, the use of third generation synthetic turf for sporting grounds and schools in Australia is rapidly expanding. This third generation synthetic turf has performed satisfactorily and been accepted for other football codes including, rugby union, soccer and American football, but the suitability for Australian football has not previously been considered. Given that most Australian football fields are also used for cricket, any proposed changes to the surface has to consider suitability for both sports.

It is imperative that synthetic surfaces meet the specific performance and safety requirements of the different sports played on them. Consequently, sports such as hockey, soccer and rugby union have established specifications for synthetic turf to fulfil in order to become accredited grounds and satisfy insurance requirements [2-4]. To date no such standards have been set for Australian 
football or cricket outfields. The demands of these two sports differ greatly, for example, Australian football is typically played on longer grass involving a lot of player contact with the surface, but in the game of cricket the interaction of the ball with the surface is of utmost importance. However, before synthetic turf manufacturers can develop a suitable surface for this multisport use, it is critical to establish performance and safety standards based on currently used natural turf surfaces so that the requirements within each sport are maintained.

This project aimed to establish a set of standards that could be tested in the laboratory setting, which would inform synthetic turf manufacturers of the minimum requirements to enable synthetic surfaces to replicate the playing and safety performance of natural turf for Australian football and cricket at community level. This paper first describes the data collection procedures and test methods undertaken and presents the results underpinning the development of the standards and secondly, proposes challenges and issues associated with the adoption of a single synthetic turf in Australia across both sports.

\section{METHODS}

Testing was undertaken on the mechanical properties of the surface and ball interactions using internationally recognised testing equipment and procedures as described below. The tests included critical fall height, hardness, rotational traction, friction/abrasion, ball roll, vertical ball rebound, and angled ball behaviour. Selection of these seven tests was based on the playing demands of Australian football and cricket with some consideration of the tests used for the other football codes and the existing international standards.

Tests were undertaken on six community level natural turf fields, once during each sport's season, to establish the playing characteristics of the surfaces used for the two sports. Testing took place during a cricket and Australian football season to account for the different conditions experienced by the two sports. Two types of grass species were dominant on the fields tested, firstly couch 
grass which is the most common during the cricket season and secondly, couch grass over sown with rye grass, the most common combination during the Australian football season, particularly in more southern parts of the country. Grass length varied between $30-50 \mathrm{~mm}$ on football fields and $15-20 \mathrm{~mm}$ on the cricket fields. In addition, samples of couch grass over sown with rye grass were grown and tests were undertaken in the climate chamber at temperatures of 10, 35 and 45 degrees Centigrade with $40 \%$ humidity to identify possible changes in surface properties at different temperatures. These temperatures were selected to represent the range of temperatures experienced by football and cricket players throughout the country and to ensure that the standards developed accounted for any differences, particularly with the surface-ball interactions. Each test was repeated five times in the laboratory setting (with the exceptions identified in Table 1) and in the field based testing five trials of each test were recorded on a minimum of four locations on the field.

\subsection{Surface Property Tests}

\section{Critical Fall Height}

The critical fall height $(\mathrm{CFH})$ was determined by dropping an instrumented head form from various heights onto the surface measuring the deceleration at impact using a Uniaxe Impact Tester. The Australian/New Zealand Standard (AS/NZS 4422) [5] procedure was used and consisted of dropping a $5 \mathrm{~kg}$ head form from incrementally increasing drop heights from low to high, and from this the Head Injury Criterion (HIC) value and the impact force (Gmax) were calculated. A single test comprised four consecutive drops on the same site and repeated three times at different sites to determine the height $(\mathrm{m})$ that a player could fall from head first onto the surface without sustaining a traumatic head injury.

\section{Hardness}

The equipment used by many Local Councils in Australia to assess ground hardness of natural turf playing fields is the Clegg hammer and hence was utilised in this study [1]. A $2.25 \mathrm{~kg}$ weight (hammer) encasing an accelerometer was dropped from a height of $45 \mathrm{~cm}$ through a vertical guide 
tube. The deceleration on impact was measured in gravities (g). The commonly accepted procedure comprises four sequential drops on the same site, with the fourth drop recorded as the hardness measure [6]. However, in accordance with previous turf research $[7,8]$, the results from the first, third and fourth drops have all been reported in this study.

\section{Traction}

Rotational traction was measured using a Studded Boot Apparatus. This device comprised of a 40 $\mathrm{kg}$ circular weight at the end of a steel pole with six Australian football studs (16 $\mathrm{mm} \pm 2 \mathrm{~mm}$ in length) arranged in a circular pattern on the base. The device was lifted vertically and dropped from $150 \mathrm{~mm}$ onto the turf. A torque wrench inserted into the handle at 90 degrees was used to record the amount of torque $(\mathrm{Nm})$ required to start the rotation of the studs in the ground. Football studs are commonly used on the base of this apparatus; however, for the purpose of this research the rotational traction provided by plastic cricket cleats $(5 \mathrm{~mm} \pm 1 \mathrm{~mm})$ and cricket spikes $(10 \mathrm{~mm} \pm$ $1 \mathrm{~mm}$ ) was also measured. The same circular pattern in the base plate was used for the cricket cleats and spikes.

\section{Abrasion/Friction}

A new device was developed to measure the damage to a thin polyurethane membrane(a skin-like material) when dragged over the surface (Figure 1). A block of wood $\left(10 \mathrm{~cm}^{2}\right.$ and $240 \mathrm{~g}$ mass) was covered with a skin-like covering (a thin polyurethane membrane) and the friction force and coefficients of friction were measured by moving the block over a smooth, clean surface. The friction force was calculated by the force required to move the block on the surface and the coefficient of friction by dividing the friction force by the weight force of the block. The device was then placed on the test surface (i.e. the natural turf). Following the assessment of an approximate weight force of a player's upper limb landing on the surface, a $20 \mathrm{~kg}$ weight was added to the block. The weight was dragged across the surface for $1 \mathrm{~m}$ at $5 \mathrm{~m} / \mathrm{s}$. The friction force and coefficient of friction were calculated again and the change in friction force between the pre and 
post drag measures and the second coefficient of friction were recorded as abrasion and friction respectively.

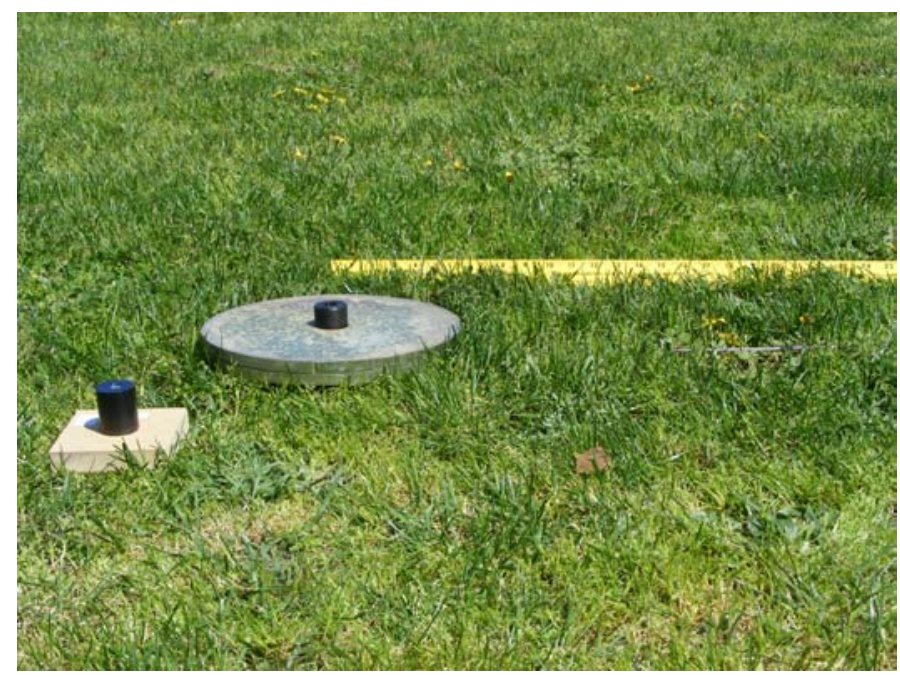

Fig 1. University of Ballarat device for measuring abrasion and surface friction.

\subsection{Ball Interaction Tests}

The cricket ball used for all these tests was a two seam ball of weight $160 \pm 10 \mathrm{~g}$, the Australian football was $720-730 \mathrm{~mm}$ in circumference and inflated to $70 \pm 3 \mathrm{kPa}$ and the soccer ball weighed $430 \pm 20 \mathrm{~g}$ and was inflated to $80 \pm 5 \mathrm{kPa}$.

\section{Ball Roll}

The test used to measure the ball roll involved rolling a ball, both Australian football and cricket, down a $1 \mathrm{~m}$ ramp with a 45 degree inclination. The dimensions of the ramp were in accordance with the BS EN 12234 [9]. The changes in the ramp for the cricket test can be seen in Figure 2. The ball was released by the operator removing their fingertips from the ball; and the cricket ball was positioned with the seam of the ball across the ramp. Electronic timing gates were used to measure the change in velocity over a distance of $1.0 \mathrm{~m}$ with the time and velocity recorded at 0.2 $\mathrm{m}, 1.2 \mathrm{~m}$ and $1.4 \mathrm{~m}$ from the initial timing gate. The positioning of the timing gates was influenced by the distance available in the climate chamber. The change in velocity over the $1 \mathrm{~m}$ distance was recorded. The higher the positive change in velocity the slower the surface and conversely the higher the negative change, the faster the surface. 


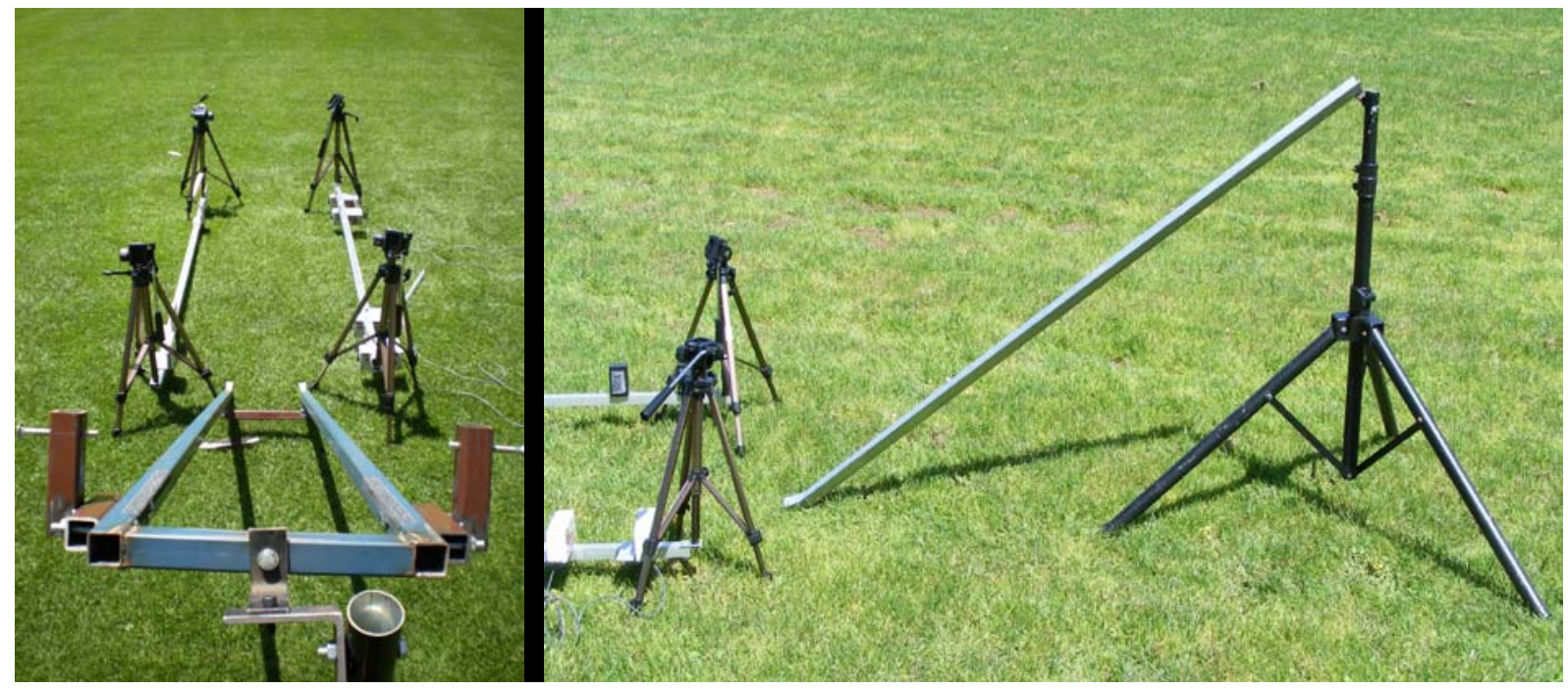

Fig 2. Ball roll test set-up for (a) Australian football, (b) change of ramp for the cricket ball roll tests.

\section{Vertical Ball Rebound}

The Vertical Ball Rebound Test was conducted by dropping the Australian football and cricket ball from $2 \mathrm{~m}$ and measuring its rebound height. The rebound height of the ball was pre and post tested according to BS EN12235 [10]. It was possible to achieve a consistent drop with the Australian football if the pressure of the ball was maintained at $70 \pm 3 \mathrm{kPa}$.

\section{Angled Ball Rebound}

The Angled Ball Rebound Test was performed by releasing the ball through an electronic ball machine (different machines for each ball) and measuring the change in horizontal velocity before and after the ball hit the surface. It was not possible to achieve a consistent angled ball interaction with the Australian football, therefore, a soccer ball was used for this test along with the cricket ball. The soccer ball was released at $50 \pm 5 \mathrm{~km} / \mathrm{hr}$ and at an angle of $15 \pm 2$ degrees from the horizontal and the cricket ball was released at $75 \pm 5 \mathrm{~km} / \mathrm{hr}$ also at an angle of $15 \pm 2$ degrees. The difference in velocity before and after the ball connected with the surface was measured in $\mathrm{km} / \mathrm{hr}$ using a radar gun (sampling rate of $33.4-36.0 \mathrm{GHz}$ and accuracy rate of $\pm 0.16 \mathrm{~km} / \mathrm{hr}$ ). This difference was then converted from an absolute to a percentage change. The test methods were similar to BS EN 13865 [11] but varied according to the equipment used. 


\section{RESULTS}

The means and 95\% Confidence Intervals $(\mathrm{Cl})$ for all tests are presented in Table 1 . The CFH ranged from $0.8 \mathrm{~m}-1.0 \mathrm{~m}$ with a mean of $0.9 \mathrm{~m}$ (95\% Confidence Interval (Cl); $0.80-1.06 \mathrm{~m})$. Although higher values were recorded in the climate chamber on the uncompacted grass samples, the results were similar across the three different temperatures (Table 1). 
Table 1. Means and 95\%Cls for surface properties in the field and climate chamber tests.

\begin{tabular}{|c|c|c|c|c|c|c|c|c|}
\hline \multirow[t]{3}{*}{ Property } & \multirow{2}{*}{\multicolumn{2}{|c|}{ Field Test }} & \multicolumn{6}{|c|}{ Climate Chamber } \\
\hline & & & \multicolumn{2}{|c|}{$\begin{array}{c}10^{\circ} \\
\text { Centigrade }\end{array}$} & \multicolumn{2}{|c|}{$\begin{array}{c}35^{\circ} \\
\text { Centigrade }\end{array}$} & \multicolumn{2}{|c|}{$\begin{array}{c}45^{\circ} \\
\text { Centigrade }\end{array}$} \\
\hline & Mean & $95 \% \mathrm{Cl}$ & Mean & $95 \% \mathrm{Cl}$ & Mean & $95 \% \mathrm{Cl}$ & Mean & $95 \% \mathrm{Cl}$ \\
\hline $\mathrm{CFH}(\mathrm{m})$ & 0.9 & $0.8-1.1$ & 1.6 & $N C^{*}$ & 1.5 & $N C^{*}$ & 1.6 & $N C^{*}$ \\
\hline Hardness (g) & 136.0 & $\begin{array}{l}104.5- \\
167.6\end{array}$ & 35.3 & $24.0-46.7$ & 45.5 & $37.6-53.4$ & 38.7 & $\begin{array}{l}33.5- \\
43.8\end{array}$ \\
\hline $\begin{array}{l}\text { Traction - football } \\
(\mathrm{Nm})\end{array}$ & 30.1 & $\begin{array}{l}22.8- \\
37.3\end{array}$ & 43.0 & $42.0-44.0$ & 43.0 & $43.0-43.0$ & 43.0 & $\begin{array}{l}42.0- \\
44.0\end{array}$ \\
\hline $\begin{array}{l}\text { Traction - cleats } \\
(\mathrm{Nm})\end{array}$ & 13.1 & $9.7-16.5$ & NT & & NT & & NT & \\
\hline $\begin{array}{l}\text { Traction - spikes } \\
(\mathrm{Nm})\end{array}$ & 22.3 & $\begin{array}{l}20.5- \\
24.0\end{array}$ & NT & & NT & & NT & \\
\hline $\begin{array}{l}\text { Abrasion (\% } \\
\text { change ) }\end{array}$ & 40.0 & $\begin{array}{l}37.7- \\
42.3\end{array}$ & NT & & NT & & NT & \\
\hline Friction $(\mu)$ & 0.51 & $\begin{array}{l}0.50- \\
0.53\end{array}$ & NT & & NT & & NT & \\
\hline $\begin{array}{l}\text { Ball roll (football) } \\
(\%)\end{array}$ & -4.6 & $-5.1--4.1$ & 6.3 & $4.8-7.7$ & 10.3 & $9.0-11.5$ & 12.7 & $\begin{array}{l}12.4- \\
12.9\end{array}$ \\
\hline $\begin{array}{l}\text { Ball roll (cricket) } \\
(\%)\end{array}$ & 9.8 & $9.2-10.3$ & -4.0 & $-4.6--3.4$ & -8.2 & $-8.8--7.8$ & -7.7 & $-8.5--6.9$ \\
\hline $\begin{array}{l}\text { Vertical rebound } \\
\text { (football)(m) }\end{array}$ & 0.9 & $0.8-1.0$ & NT & & NT & & NT & \\
\hline $\begin{array}{l}\text { Vertical rebound } \\
\text { (cricket) (m) }\end{array}$ & 0.4 & $0.4-0.4$ & NT & & NT & & NT & \\
\hline $\begin{array}{l}\text { Angled rebound } \\
\text { (football) (\%) }\end{array}$ & 53.0 & $\begin{array}{l}48.1- \\
58.0\end{array}$ & NT & & NT & & NT & \\
\hline $\begin{array}{l}\text { Angled rebound } \\
\text { (cricket) (\%) }\end{array}$ & 38.0 & $\begin{array}{l}34.4- \\
40.1\end{array}$ & NT & & NT & & NT & \\
\hline
\end{tabular}

$N C^{*}=$ Not calculated. Only one $\mathrm{CFH}$ value was recorded in the climate chamber at each temperature to ensure a unique piece the sample was used for each test.

$N T=$ Not tested. 
In Australia, it is accepted practice that a Clegg hammer hardness reading of over $120 \mathrm{~g}$ [7] declares the field unsuitable for use, resulting in ground closure. In this project, values for the community level fields displayed higher levels of hardness where the first drop ranged from $94 \mathrm{~g}-$ $121 \mathrm{~g}, 143 \mathrm{~g}-158 \mathrm{~g}$ for the third drop and $152 \mathrm{~g}-166 \mathrm{~g}$ for the fourth drop (Figure 3). Similar to the $\mathrm{CFH}$, the hardness reading did not differ between the three temperatures in the climate chamber $(p=0.22)$ (Table 1$)$ but were lower than the field tests due to new, uncompacted samples.

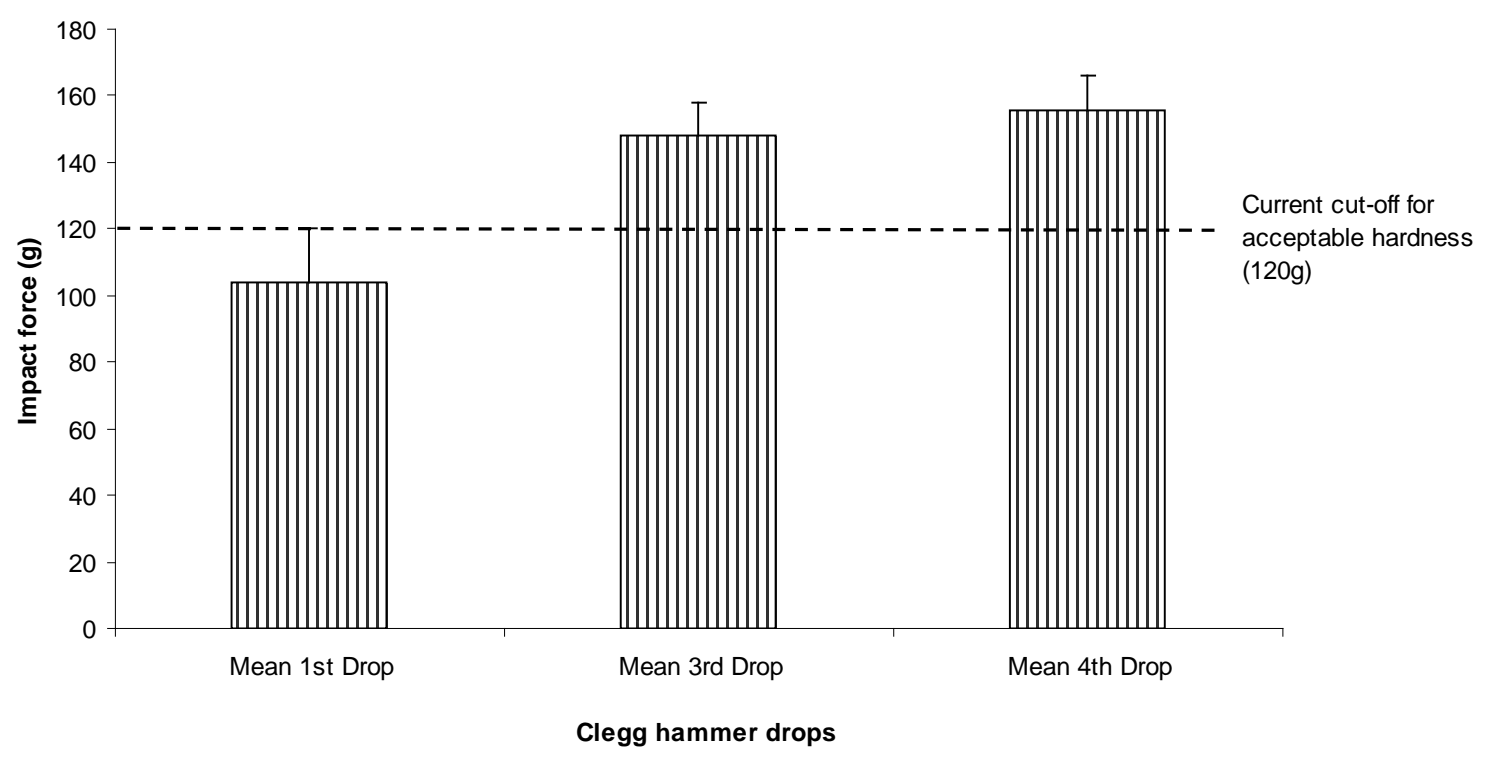

Fig 3. Mean values for Clegg hammer on community level grounds across drops 1,3 and 4, with $95 \% \mathrm{Cls}$ represented by $\mathrm{Y}$ error bars.

Rotational traction values ranged from $20-42 \mathrm{Nm}$ for football studs, $7-15 \mathrm{Nm}$ for cricket cleats, and $21-24 \mathrm{Nm}$ for cricket spikes. Despite the slightly higher traction readings in the climate chamber, similar results were recorded across the three different temperatures for the football studs traction (Table 1). The coefficient of friction ranged from $0.50-0.53$ and abrasive properties of the surface were reflected in a $38-42 \%$ change in friction force in the field testing (Table 1). 
In the three ball interactions tests, the results were significantly influenced by the ball for each sport. The changes in velocity of the ball in the ball roll test ranged from $-2 \%$ to $-7 \%$ for football and $+17 \%$ to $+21 \%$ for the cricket ball roll. This indicated that the football consistently sped up (perhaps due to the slope of the field or shape of the ball) and the cricket ball slowed down. The ball roll test was the only ball-related test to be undertaken in the climate chamber. For the vertical ball rebound test, the football rebounded to between $0.76-1.0 \mathrm{~m}$ and consistently to $0.4 \mathrm{~m}$ for the cricket ball. The decrease in velocity for the soccer ball angled rebound ranged from $47-64 \%$ and $32-44 \%$ for the football and cricket ball respectively (Table 1).

All the results previously presented in this section culminated in a set of standards (Table 2) that can be tested in the laboratory setting, for synthetic turf companies to satisfy for a product to be accepted for installation on a community level Australian football/cricket field. The final values or ranges of values were primarily derived from these results, particularly the ball interaction standards. However, data from elite level grounds previously collected and reported elsewhere [12] were also considered for the parameters with a safety component, for example $\mathrm{CFH}$, hardness and traction.

Table 2. Summary table of standards for synthetic turf for Australian football and cricket at community level.

\begin{tabular}{c|c}
\hline Characteristic & Community Level \\
\hline \hline${ }^{*}$ Critical Fall Height & $1.2 \mathrm{~m}$ \\
Hardness & $65 \mathrm{~g}-120 \mathrm{~g}$ \\
Abrasion -Change in Friction Force & \pm 50 \\
Friction -Coefficient of friction & $0.35-0.75$ \\
Traction Football Studs & $25 \mathrm{Nm}-50 \mathrm{Nm}$ \\
Traction Cricket Spikes & $15 \mathrm{Nm}-25 \mathrm{Nm}$ \\
Traction Cricket Cleats & $7 \mathrm{Nm}-15 \mathrm{Nm}$ \\
Ball Roll Football & $\pm 10 \%$ \\
Ball Roll Cricket & $\pm 15 \%$ \\
Vertical Ball Rebound Football & $0.6 \mathrm{~m}-1.0 \mathrm{~m}$ \\
Vertical Ball Rebound Cricket & $0.1 \mathrm{~m}-0.4 \mathrm{~m}$
\end{tabular}




\section{DISCUSSION}

The results presented in this paper represent the findings of mechanical properties of the surface and ball interactions as measured from the natural turf setting to underpin the standards developed for synthetic turf use for Australian football and cricket. The seven tests selected, and consequently included in the AFL/CA standards, are a complete set of laboratory based tests required to ensure the playing characteristics of Australian football and cricket are maintained. These standards include both the playing characteristics of the sports, for example the ball interactions, hardness and traction, and the safety components of critical fall height, hardness, traction, and abrasion. Some of the challenges and issues of the dual sport demands of the surface will now be discussed in addition to a number of other potential issues that arose during the testing phase.

Rugby union is currently the only other sport that includes the $\mathrm{CFH}$ as a requirement for synthetic turf standards and in this study the $\mathrm{CFH}$ results obtained were similar to the requirements $(>1.0 \mathrm{~m})$ for rugby union [2]. An integral part of the game of Australian football is the player jumping for a mark (i.e. to catch the ball and receive a free kick) and the heights reached by the football players would be similar to the line-outs in rugby union. Basing the $\mathrm{CFH}$ requirement on the lower fall heights of less than $1.0 \mathrm{~m}$ produced on the harder surfaces on the community level fields may not be an issue in cricket but was perceived as a potential problem for Australian football at senior community level. Consequently, the criterion for critical fall height was set at the same height as that achieved on elite level Australian football fields [12]. Given the expected dispersion and potential loss of infill over time, it would seem reasonable to suggest that the shock pad or e-layer will play a critical role in maintaining this safety standard for the life span of the playing surface. 
The ability to change direction is a fundamental skill in the game of Australian football and to a lesser extent in cricket. For the athlete, high rotational traction equates to a greater tendency for the foot to grip during changes of direction and low rotational traction means the shoe tends to release from the surface more easily. There is strong evidence that excessive resistance to rotation at the shoe-surface interface increases the risk of foot fixation and hence the risk of lower extremity injuries [13-16]. The rotational traction testing was undertaken with the studs, cleats and spikes from current natural turf Australian football and cricket footwear to accommodate the footwear from both sports. The differences identified in the results led to the inclusion of the football studs and cleats in the set of standards for the synthetic turf products to satisfy. Although the internationally recognised equipment and test procedure for rotational traction was followed, a notable limitation observed during the testing was the lack of similarity between the stud pattern on the Studded Boot Apparatus and the most popular soles currently worn by Australian football and cricket players. Further research is required to determine both the validity and reliability of the current Studded Boot Apparatus in relation to the player surface interactions during these two sports. Additionally, it was anticipated that the cricket spikes had potential to get caught in the synthetic fibres and hence produce even higher torque values. Consequently, some pilot testing was undertaken on various samples of synthetic turf in the laboratory and in situ (unpublished work). Very high torque results were recorded ranging between $19-77 \mathrm{Nm}$. Previous research has suggested that $40-55 \mathrm{Nm}$ is the ideal traction on an Australian football surface [17]. Therefore, the increased injury risk and potential damage to the fibres of the synthetic turf has strong implications for the use of appropriate footwear on these surfaces. It was agreed by the sporting organisations that players would be dissuaded from wearing cricket spikes on the synthetic surfaces and traction testing with spikes would only be undertaken in the event of field installation with a synthetic outfield and a natural wicket area. With the introduction of synthetic fields targeting the community level in Australia, the cost associated with purchasing additional synthetic turf specific footwear is an important consideration. 
A common perception is that synthetic turf has a highly abrasive property and results in skin abrasions and friction burns when the players slide/land on it. That may have been a valid complaint on the earlier generations of turf which had a high sand content but it is postulated that it may not transpire on third generation turf with the introduction of the longer fibres and a reduction in player contact with the sand infill (being beneath the rubber infill). Since contact with the ground is customary in the game of Australian football and cricket, it was essential to assess the interaction of the surface with skin. The lower the coefficient of friction and the lower the change in friction force, the less chance the player has of sustaining a friction burn or skin abrasion from the surface. The device used in this research was developed due to the accessibility of equipment used in other sport standards and finance available. While no formal validity testing was undertaken, the results and hence standards set were similar to other sports [4]. Further work is currently being undertaken on the reliability of this device. On one of the natural turf surfaces, sand had been swept through prior to testing which increased the scores obtained in this study. However, that was excluded in the determination of the final standards for this property. The variations in the type of infill will influence the results for this property and to date there is a lack of evidence on the injury incidence of abrasions and friction burns on third generation turf.

The predictability and consistency of a ball rolling across the playing surface is of utmost importance in the game of cricket. As the batter hits the ball along the ground he/she needs to be able to anticipate how far it will roll to determine the number of runs he/she can attempt to score. Although it is not so crucial to the game of Australian football, if the roll of the ball changed or became unpredictable it may result in players altering their habits and potentially alter the nature of the game. The increase in speed of the ball in the football roll tests was unexpected and may be due to the slope on the fields (that was not obvious or measured on the day of testing) or the shape of the ball. Appropriate maintenance of the surface and thus uniformity across the surface will be critical in satisfying and maintaining this standard and preserving game characteristics. Additionally, in both Australian football and cricket, the height to which the ball bounces, both in a vertical direction and an angled rebound, is important for the player for catching, kicking or 
punching the ball away. If the ball bounces higher or lower than expected it may cause injury or result in the player's inability to perform the desired task. Similarly, if the ball rebounds off the surface at an unanticipated speed or trajectory, the risk of sustaining an injury or the player's inability to perform the required task may increase. For example, if the cricket ball rebounds at a greater speed than anticipated it may strike the face potentially resulting in injury. To date very little has been published on the mechanisms of injury or injury risk on third generation synthetic turf. Most of the work has been undertaken in soccer and has indicated that there does not appear to be an increase in injury incidence on the third generation synthetic turf but a possible increased risk of ankle injuries particularly during match play [18-20]. Further research needs to be undertaken to ascertain the full extent of the injury risk on $3^{\text {rd }}$ generation synthetic turf.

In addition to the results discussed, two other potential issues emerged concerning the safety of Australian football and cricket players on the third generation synthetic turf surfaces. During the summer months, temperatures in excess of 35 degrees Centigrade are recorded in many parts of Australia. Therefore, heat is a major concern for many sports and can result in frequent ground closures. The use of black crumbed rubber as an infill on these surfaces, in the absence of water as an option for cooling the surface, may pose a problem with increased radiant heat. Although heat policies are practical countermeasures to the heat problem, this solution would seem to contradict the reasons for the introduction of synthetic turf fields to replace natural turf fields in drought regions in the first instance. Similar to the game of rugby, Australian football players and cricket players land on the surface throughout the game with various body parts. The spray of rubber particles into the eye, inhaled into the respiratory tract or ingested through the mouth could potentially place an athlete at risk. To date this issue has not been explored or reported on and will require detailed injury surveillance to confirm or refute the issue. This was the first time synthetic surfaces were considered for Australian football and cricket outfields and will hopefully lead the way for future developments in this area. 


\section{CONCLUSIONS}

To the authors' knowledge, this is the first research project to develop a single set of standards for synthetic turf for dual sport use. The process described in this paper highlights the importance of careful consideration of the characteristics of both games and the use of equipment from both sports in the testing methods. The standards presented were established within the limitations of the equipment available; however, there is a substantial amount of research that needs to be carried out to determine the validity of the testing equipment and procedures in terms of replicating player surface interactions for Australian football and cricket. In addition, further research needs to be undertaken to quantify the contribution of the infill to heat illnesses and the potential injury risk associated with the rubber infill spray. These standards have now been accepted by the Australian Football League and Cricket Australia and the use of synthetic surfaces for Australian football and cricket is imminent.

\section{ACKNOWLEDGMENTS}

The authors would like to acknowledge the funding for this project by the Australian Football League, Cricket Australia, JLT Trustees and Sport \& Recreation Victoria to undertake this research project. The authors would also like to thank lan Chivers and Rodney Hall for their assistance.

\section{REFERENCES}

1 Otago, L., Swan, P., Chivers, I., Finch, C., Payne, W. and Orchard, J. Ground conditions and injury risk - implications for sports grounds assessment practices in Victoria. (University of Ballarat, Ballarat, 2007).

2 International Rugby Board. REGULATION 22; Standard relating to the use of artificial playing surfaces, (2003).

3 International Hockey Federation (FIH). Handbook of performance requirements and test procedures for synthetic turf hockey pitches, (2008). 

football turf: Handbook of requirements, (2009).

5 Standards Australia \& New Zealand. AS/NZS 4422 Playground surfacing - specifications, requirements and test methods, (1996).

6 Clegg, B. An impact testing device for in-situ base course evaluation. Proceedings of the 8th Australian Road Research Board Conference, (1976).

7 Chivers, I. and Aldous, D. Performance monitoring of grassed playing surfaces for Australian Rules football. Journal of Turfgrass and Sports Surface Science, 2004, 70, 73 - 80.

8 McNitt, A.S. and Petrunak, D.M. Evaluation of playing surface characteristics of various in-filled systems. (PennState, Department of Crop and Soil Sciences, 2006).

$9 \quad$ British Standards Institution. EN 12234: Surfaces for sports areas - Determination of ball roll behaviour, (2002).

10 British Standards Institution. EN 12235: Surfaces for sports areas - Determination of vertical ball behaviour, (2004).

11 British Standards Institution. EN 13865: Surfaces for sports areas - Determination of angled ball behaviour.Tennis, (2003).

12 Twomey, D., Otago, L., Saunders, N. and Schwarz, E. Development of standards for the use of artificial turf for Australian football and cricket. (University of Ballarat, Ballarat, 2008).

13 Torg, J.S., Stilwell, G. and Rogers, K. The effect of ambient temperature on the shoesurface interface release coefficient. American Journal of Sports Medicine, 1996, 24(1), 79-82.

14 Orchard, J. Is there a relationship between ground and climatic conditions and injuries in football? Sports Medicine, 2002, 32(7), 419-432.

15 Chivers, I., Aldous, D. and Orchard, J. The relationship of Australian football grass surfaces to anterior cruciate ligament injury. International Turfgrass Society Research Journal, $2005,10,327-332$. 
16 Nigg, B. and Segesser, B. The influence of playing surfaces on the load on the locomotor system and on football and tennis injuries. Sports Medicine, 1988, 5(6), 375 - 385.

17 Aldous, D., Chivers, I. and Kerr, R. Players perceptions of Australian football league grass surfaces. International Turfgrass Society Research Journal, 2005, 10, 1-8.

18 Ekstrand, J., Timpka, T. and Hagglund, M. Risk of injury in elite football played on artificial turf versus natural grass: a prospective two-cohort study British Journal of Sports Medicine, 2006, 40(12), 975-980.

19 Fuller, C.W., Dick, R.W., Corlette, J. and Schmalz, R. Comparison of the incidence, nature and cause of injuries sustained on grass and new generation artificial turf by male and female football players. Part 1: match injuries. British Journal of Sports Medicine, 2007, 41(suppl_1), i20-26.

20 Steffen, K., Andersen, T.E. and Bahr, R. Risk of injury on artificial turf and natural grass in young female football players. British Journal of Sports Medicine, 2007, 41(suppl_1), i33-37. 